\title{
Strategies to Use Deceptive Statements in the Iranian Academic Context
}

\author{
Mohammad Aliakbari ${ }^{1} \&$ Khalil Tazik ${ }^{1}$ \\ ${ }^{1}$ Department of English, Ilam University, Ilam, Iran \\ Correspondence: Mohammad Aliakbari, Department of English Language and Literature, Faculty of Literature, Ilam \\ University, Ilam, Iran. Tel: 91-83-413-283. E-mail: maliakbari@hotmail.com
}

Received: May 30, 2015

Accepted: June 24, 2015

Online Published: June 25, 2015

doi:10.5430/elr.v4n2p73

URL: http://dx.doi.org/10.5430/elr.v4n2p73

\begin{abstract}
Lying, as a deceptive act in social interactions, has received much attention among social psychologists. Studies in this area mostly aim at developing lying taxonomies and finding verbal and non-verbal clues for detecting liars. However, it seems that the generalizability of their findings, because of cultural and contextual differences, is limited. Hence, admitting the fact that lying can be context and culture-specific, this study attempted to investigate lying among professors and students in the Iranian universities, to developa taxonomy for lying, and also to examine the role of gender and status in this relation. For this aim, frequent interactions between students, professors, and university staffs were identified and, based on these interactions, a questionnaire was designed and administered to 120 students and 80 professors. Results revealed 18 types of lies among which 'projection' and 'forgetting' were among the most frequent lies. Same-gender parings were found to tell more lies to each other. It was also found that professors and students tend to tell more lies to higher status people.
\end{abstract}

Keywords: Lying, Deception, Taxonomy, Gender, Professors and students

\section{Introduction}

\subsection{Defining lie}

Various definitions have been proposed for lying. Ekman (1997) regarded lying as a kind of deception. For him two specific features of lying can distinguish it from other deceptive notions: the intent of lying, i.e., the liar purposefully and deliberately tries to mislead the target and the target's unawareness of the liar's intention. For Alpert and Noble (2009), "a lie is any intentionally deceptive message communicated either verbally or in writing" (p. 3). They believe that any intentional conduct, spoken or written, that conveys an untrue message to the receiver is regarded as a deceptive message. Therefore, silence and hiding the truth can be regarded as a lie. It seems that for Alpert and Noble (2009) lying and deception are similar.

However, for Mahon (2007, 2008), lying and deception are different. According to Mahon (2007), lying is not a perlocutionary act. When a person lies, the effects of lie on the target, acceptance or rejection, are not the matter - an act of lying may have occurred anyway. Mahon (2008) contrasted "lie" and "deception" in a way that the act of lying is produced regardless of its effects while deceiving is necessarily a perlocutionary speech act. He has reviewed various definitions to lying and proposed two best definitions, which are modified forms of the definition advanced by Kupfer (1982), as follows:

1. To lie (to another person) = to make a believed-false statement (to another person) with the intention that that statement be believed to be true (by the other person)

2. To lie (to another person) = to make a believed-false statement (to another person), either with the intention that that statement be believed to be true (by the other person), or with the intention that it be believed (by the other person) that that statement is believed to be true (by the person making the statement), or with both intentions. (p. 227-228)

Following all the definitions mentioned above, in the present study, any false, untrue, or misleading statement that people say without any attention to the believing, acceptance, rejection, or the effects of the mentioned statement on the target is regarded as a lie. In the following section, most of the recent studies on lying will be reviewed and the reason for doing this study will be elaborated on. 


\subsection{Studies on lying}

Lying, as an attractive topic for everyone (Meibauer, 2005), has received much attention in recent years (e.g., Vrij et al. 2000; Newman et al. 2003; Johannesson\&Dreber, 2008; Alpert \& Noble, 2009). Most of these studies tended to find evidence either for classifying or detecting different types of lies. For each tendency, some studies are given below.

Regarding lie classification, Alpert and Noble (2009) noted that lies can be illustrated on a continuum: at one end excusable and justifiable lies stand and at the other end intentional and malicious lies that take one of the three forms of deceptive action, failure to bring forward information, and creation of false evidence. In the middle of the continuum, they termed administrative lies (lies aimed at preventing some type of employment), which are more difficult to assess. Respecting this type of classification, the most outstanding taxonomy of lies can be attributed to DePaulo et al. (1996) in which they classified lies in terms of content, reason, type, and referent. They reported that content of lies included feelings, achievements, knowledge, actions, plans, whereabouts, explanations, reasons, facts, and possessions; reasons for lying were either self or other-oriented; types of lies were outright, exaggerations, and subtle; and lies referred to liar, target, other person, or object and event. These findings were obtained from both undergraduates and laypersons.

In DePaulo's et al. (1996) study, though expanding the area of study to two broad contexts may help to generalize the results more confidently, but the specificity of the lies for each context and interaction were not explored in their study. Moreover, most of the conducted studies on lying are limited to the United States. Sharon and Amir (1988) reported that, according to the international researchers, many of the social psychologists' findings in America cannot be replicated cross-culturally. Therefore, the generalizability of their findings is mainly culture-specific. For instance, in the Iranian context, Internet frequent disconnection is a common phenomenon and a good excuse for delay in doing research projects, in recording students' scores, etc. whereas this excuse may not be acceptable for Americans. These differences confuse the cross-cultural lie classification. Therefore, it seems that developing the taxonomy of lie should be done across different cultures in order to identify common and exclusive types of lies for each context and culture.

Newman et al. (2003) investigated the features of linguistic style that distinguish liars and truth tellers. They state that though liars may have control over the content of their stories, analyzing the style of language can reveal the underlying state of their mind during telling a false or true story. In other words, liars can be identified by the way they utter their words. For this aim, they analyzed five independent samples via computer-based text analysis. Results indicated that liars showed lower cognitive complexity, "used fewer self-references and other references, and used more negative emotion words" (p. 665). They discussed that findings are helpful for detecting liars when they are manipulating the language to appear as truthful. Likewise, Hancock et al. (2008) investigated the linguistic profiles of liars in synchronous, text-based Computer-Mediated Communication (CMC). They reported more words, more sense-based words, and fewer self-oriented and more other-oriented pronouns for liars than truth tellers. Hancock et al. (2009) studied the deceptive intent of Instant Messages (IM) among 43 undergraduates. They wanted the participants to record deceptive IM messages. Results of their analysis indicated that one-tenth of the messages was deceptive among which one-fifth of them was butler lies. They define butler lies as the lies that are used for polite initiation and termination of messaging. They classified butler lies as smooth exits, lying about promised communicationand lying to excuse or justify communicative behavior. As a complement to these studies, recently, papers presented at the $13^{\text {th }}$ conference of the European chapter of Association for Computational Linguistics (EACL, 2012) attempted to develop methods for detecting lies through text analysis.

Some researchers have analyzed lie indications via videotaped clips in which people are telling the truth and lies. For instance, Vrij et al. (2000) studied the ways deception can be detected via analysis of verbal and nonverbal behavior. They contend that to catch liars researchers managed to observe them, listen to them, or measure their physiological responses. Following these three possible ways, they wanted 73 nurses to watch a film and identify either lie or truth told in the film. The interviews were recorded and analyzed with the Criteria-Based Content Analysis technique (CBCA) and the Reality Monitoring technique (RM). Results revealed the contribution of nonverbal behavior to the deceit detection. However, they noted that to increase the percentage of detection, all three techniques should be taken into account. Likewise, Forrest and Feldman (2000) showed videotaped interviews, in which people were telling lies and truth, to 66 males and female. The participants were either highly involved or less-involved in the judging task. Results of their study showed that low-involved participants were more successful in detecting deception than highly involved ones. The reason was that nonverbal cues are more likely indicative of deception and less-involved participants would detect accurately the nonverbal behavior of liars. Hart et al. (2009) found that 
indirect methods, "having people search for particular verbal and nonverbal behavioral patterns, rather than explicitly directing them to look for evidence that another person is lying" (p. 136), are more effective for detecting liars than direct and explicit ones. In their research, they requested college students to watch a video in which half of the people tell lies and half of them do not. After the show, the participants were asked to either detect the liars or identify the changes made in the persons' mannerisms, behavior, and speech. Results indicated that those who were indirectly looking for the liars were more accurate.

Regarding culture and lying, Mealy, Stephan, and Urrutia (2007) state that "there is considerable evidence in the cross-cultural literature to suggest that different cultures may view lying differently" (p. 693). They reported that cultural dimensions such as power distance, uncertainty avoidance, and individualism/collectivism would affect lie perceptions.

To determine if the culture has any role in detecting lies, Bond and Atoum (2000), in an experimental study, found that lies can be detected cross-culturally by both university students and illiterates. They suggested that liars have some universal experiences and their behavior can reveal them. They also contend that both visual and audible cues are needed for lying detection, even though the judges have no knowledge of the liars' language.

Psychologists have usually viewed sex differences as inherent qualities within individuals and also agree that social forces can affect the gendered behaviors (Escalera, 2009). Therefore, it is hypothesized that in each interaction, in addition to factors such as situational factors, gender and status can also affect the way people use language. Lying in this regard is not an exception. Regarding sex differences in lying, DePaulo et al. (1996) and Feldman et al. (2002) found that women tell more other-oriented lies while men tell more self-oriented lies. In an experimental study within an economical setting, Johannesson and Dreber (2008), found that men are more eager to lie for monetary benefits than women. Findings of these studies and all the reviewed ones can significantly contribute to the lie detection and classification of strategies liars use to justify their actions. However, it seems that more research is required to create a broad picture of the ways this dishonest action is exercised across different countries and contexts. To fill this gap and to add new findings to the body of existing knowledge, this research aimed at studying lying among the Iranian academicians and university students.

\section{Theoretical framework}

Deception communication has recently been studied by many scholars within different experimental and natural contexts; however, as Anolli, Balconi, and Cinceri (2001) asserted, there has been no viable theoretical framework for this scientific domain. To overcome this problem, Anolli et al. (2001) proposed a new model called "Deceptive Miscommunication Theory (DeMiT)". This model "can explicate the main characteristics of deceptive communication and the local management of the deceptive message in its different expressions" (Anolli et al., 2001, p. 77). The main theoretical points of the DeMiT model are as follows:

1. A deceptive miscommunication theory should be included in a general framework capable of explaining the default communication.

2. Deceptive miscommunication is a heterogeneous communication field, with different kinds of deceptive messages.

3. Deceptive miscommunication is managed by an intentional stance characterized by an internal gradation.

4. The deceptive message follows the same mechanisms and processes of mental planning and execution as the default communication message.

5. Deceptive miscommunication is context-bound, and then requests a local management of conversational exchanges.

6. Deceptive miscommunication, like default communication, uses different kinds of linguistic and nonverbal expressions.

7. A useful explicative key to understand deception mechanism is given by the link between deception and self-deception.

Anolli et al. (2001)

In DeMiT, Anolli et al. (2001) prefer "to deal with deception as a "family" of miscommunication phenomena and processes" (p. 78). In this "family", researchers can consider self-deception and pathological frequent deceptiveness; prepared and unprepared lies, pedagogic lies and white lies. Four deceptive subfamilies are: 
a. Omission: the speaker omits to give the addressee some information that he/she thinks or knows is relevant to addressees' goals

b. Concealment: the speaker withholds and hides some information by giving the addressee some other divergent/diversionary information that is true but not relevant, in order to perpetuate false assumptions in him/her

c. Falsification: the speaker deliberately conveys to the addressee some information that he/she believes false.

d. Masking: the speaker withholds some information by giving the addressee some other false information.

In all of these situations, speakers' intention is the cornerstone of deceptive communication. According to DeMiT, intention can be either covert (hidden) or overt (ostensive). In the former, the speakers' intention to deceive the addressee by manipulating information must not be revealed; however, in the latter the speakers ostensibly manipulate information to deceive the addressee. Therefore, it seems that deceptive communication requires at least a second-order intentional system with two intentional layers: deception family and joke family (such as teasing, irony, sarcasm, parody, etc.). In the former, the speaker intends to deceive the addressee while in the latter the speaker has the intention to be disbelieved (see figure 1). This route of miscommunication implies "an increase of the degree of freedom on the part of the speaker to choose a definite path of message design according to context expectancies and cultural standards" (p. 80).

Anolli et al. (2001) also introduced high- and low-content deceptive acts and explicated the distinction between them. High-content deception

concerns a serious topic, is said in an important context, and is characterized by the presence of notable consequences and effects for the deceiver or for the addressee or even for other people", and low-content deception "regards a minor topic, can be said in any kind of context, and does not have consequences or, if any, they are of scarce importance.

In DeMiT, it is hypothesized that low-content deceptive acts can be said automatically without any preplanned or conscious thoughts. White and pedagogic lies included in this kind of deceptive acts. Also, it involves different kinds of concealment, omission, and evasive messages. Low-content deceptive messages are likely to produce in situations where deceivers feel ease and do not need specific cognitive demands in generating these kinds of messages. Instead, high-content deceptive acts have serious effects for both deceiver and deceived, and involve conscious thoughts and planning. High-content deceptive acts demand considerable cognitive complexity. In both types of deceptive acts, deceivers may move to particular linguistic styles characterized by "ambiguousness and prolixity", "concise assertiveness and elliptic avoidment" and "depersonalization" (p. 92). 


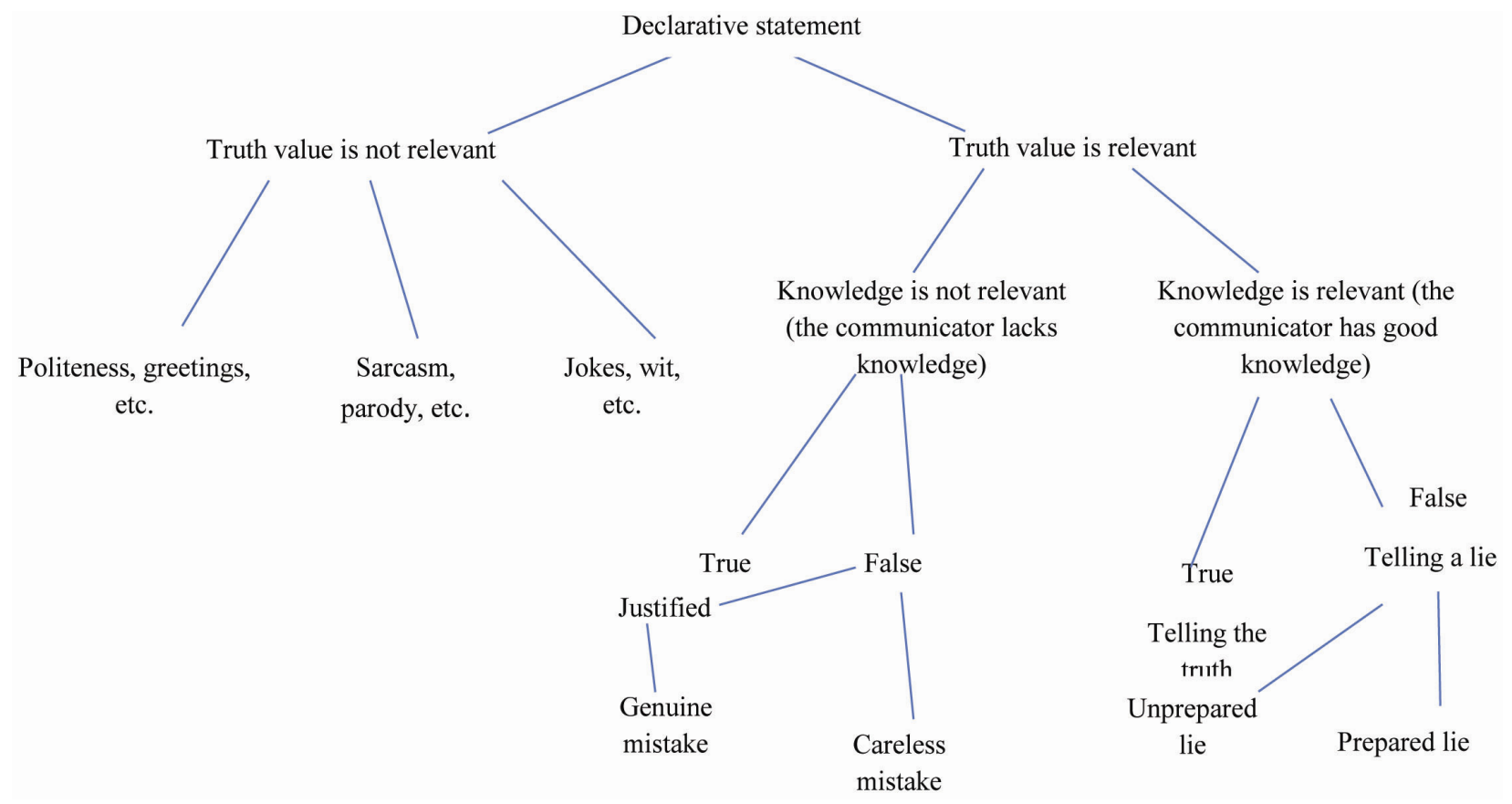

Figure 1. Route of miscommunication acts of deception adopted from Anolli et al. (2001)

\section{Focus of the study}

Iran is a religious country wherein dominant religion of people is Islam. In Islam, obeying ethical and religious principles in all aspects of life is essential. Avoiding telling a lie is among the most stressed and highlighted principles. However, strong beliefs in religion which make 'lying' a cardinal sin, on the one hand, and a conventional approach that makes 'white or permissible lies' justifiable in the Iranian society, on the other hand, confuse the matter and call for due attention. It is not new to see that people are obviously telling a lie in different situations in their everyday life and ignore the fact that lying in any type and across any situation is malicious and disrespected. To objectively demonstrate the dispersion of this phenomenon in the society, and to narrow down the topic, this study attempted to investigate lying in the Iranian academic context. The main reason for selecting this specific context is its critical role in construction and establishment of different social cultures in the society. The academic relations in Iran are characterized with both similarities as well as differences from the academic contexts in other countries. In Iran, being a university professor is a highly-respected and prestigious job. Professors are the core of academic context and possess higher status. They have the right to give passing or failing scores to their students and, in few cases, they are questioned for the given scores. Students, however, have the lower rank and follow their professors. They need to be present in all classes during the term, do their projects before the determined deadline, and take a test whenever their professors prefer. Staffs are ranked in between; they have a relationship with both professors and students. Though staff may ask questions from the professors and students, they, like students, are so cautious in their relations with professors. Therefore, sometimes in these relations and interactions any of these people may use untrue statements to keep the relations safe. To see what types of lies they may tell to each other, the following questions were formulated in this study:

1. What are the most frequently used lies across the Iranian academic context?

2. Do the frequency and types of lies differ in the same-gender parings comparing with different-gender parings? 


\section{Method}

\subsection{Participants}

The initial sample of this study was 150 undergraduate students and 100 professors. However, 30 undergraduates and 20 professors refused to complete the questionnaires, and the final participants for the study were 80 professors ( 40 males and 40 females) and 120 students (70 males and 50 females) who were randomly selected from different universities of Ilam, Iran. The age range of professors was 27 to $45(\mathrm{M}=36)$ and the students' age ranged from 18 to $31(\mathrm{M}=24.5)$. Among the professors, 65 were lecturers and 15 were assistant professors. All the students were BA students. It should hasten to say that the study mainly focused on the university students and professors; these are the students and professors who have been engaged in different situations and were asked to fill out the open-ended questions.

\subsection{Procedure}

The study followed several stages which are delineated as follows.

Stage 1: identifying interactions. In this stage, the researchers attempted to identify different interactions in which students and professors may deal with in academic contexts. After observing the interactions and interviewing some students and professors, the most frequent and significant interactions were identified which were professor-staff, professor-professor, professor-student, student-staff, student-student, and student-professor. Additionally, the role of gender in each interaction was considered.

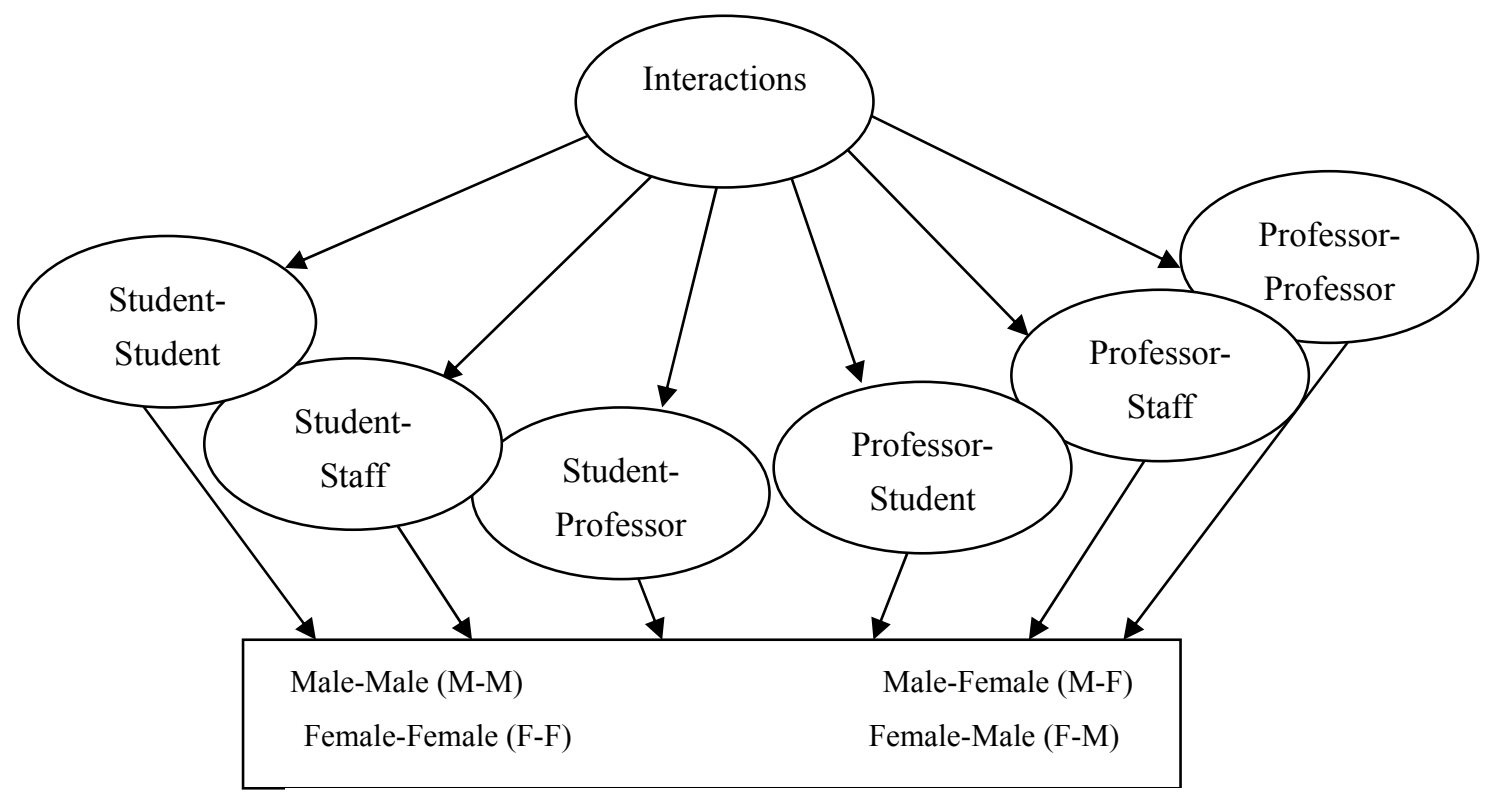

Figure 2. Possible interactions in academic contexts in Iran

Considering four gendered groupings, the 24 possible interactions were schematically represented. M-M (a male is responding to a male), M-F (a male is responding to a female), F-F (a female is responding to a female), and F-M (a female is responding to a male). For example, in Student-Student interaction, all these gender interactions have been considered, i.e., M-M: a male student is responding to male student, M-F: a male student is responding to female student, F-F: a female student is responding to a female student, F-M: a female student is responding to male student. The classification is demonstrated in figure 2.

Stage 2: developing the questionnaire. After two weeks of direct observation of students and professors in their interactions and interviewing some of them, possible occasions and events that participants could encounter were recorded and included in a questionnaire. The questions in the query would put the professors and students in a situation that they had already experienced and asked them to express what they would say in that situation, tell the truth or a lie. If the respondents selected the second option, they would be asked to write the content of the lies. The numbers of questions for each interaction were 7 questions for professor-staff, 11 questions for professor-professor, 5 questions for professor-student, 7 questions for student-student, 3 questions for student-staff, and 9 questions for student-professor. Since the frequency of interactions among students, professors, and staffs were variable and 
unequal, the numbers of questions which represent the interactions were different. After designing the questionnaire, it was piloted among 30 undergraduates and 15 professors at Ilam University, Iran. The administration process and completion of the questionnaires took 45 minutes for the professors and 40minutes for the students. After completing the questionnaire, the respondents were asked to evaluate the questions and comment on the questions. After analyzing their comments, 1 question in the professor-professor and student-professor interactions were omitted, and 2 questions in the student-professor interaction were combined. Therefore, 10 questions for professor-professor and 7 questions for student-professor interactions were remained. Answers to the questions were used for developing the taxonomy of lies.

Stage 3: developing a preliminary taxonomy of lies. In this stage, answers to the questions in each interaction, the researchers' everyday observation, and interviewing the students and professors were used to develop the academic-specific taxonomy of lies. After long debates and discussions, 9 types of lies were coded as the preliminary taxonomy. However, it was tentative and the researchers tended to modify and complete it at the next stages of the study.

Stage 4: administering the questionnaire and developing the final draft. Getting ensured of the overall coverage of the situations in the query for the frequently occurring interactions in academic context in relation with the students and professors, the questionnaire was administered among 80 professors and 120 undergraduates in different universities in Ilam, Iran. This process took a week; some of the participants preferred to take the questionnaire home and got it back later. After assembling the questionnaires, the lies told in each interaction were transcribed and, by consulting $4 \mathrm{PhD}$ candidatesin TEFL at Ilam University, they were put under the previously 9 coded lies. However, it was found that some liesremained classless; hence, new codes were required. Therefore, the process of codifying the lies resumed and the final taxonomy found to have 18 types of lies (see Table 1 for the taxonomy and definition of each lie). Also the distribution of these types of lies across the Iranian academic context, in general, and gendered groupings, in particular, was obtained.

Table 1. Taxonomy of lie strategies used by Iranian academicians, students, and staffs

\begin{tabular}{|c|c|c|}
\hline Types of lies: & $\begin{array}{c}\text { Definition } \\
\end{array}$ & Example \\
\hline Projection & $\begin{array}{l}\text { Lies that justify the actions by putting the responsibility on the shoulders of } \\
\text { something or somebody else }\end{array}$ & My car was out of order. \\
\hline Having priority in daily works & $\begin{array}{l}\text { Lies that showt the liars have priority in their daily works and firmly keap on } \\
\text { the programs }\end{array}$ & $\begin{array}{l}\text { I'm about to write a new } \\
\text { article. }\end{array}$ \\
\hline Forgetting & Lies that show people have forgotten to do something & Sorry, I forgot it. \\
\hline $\begin{array}{l}\text { Having incomplete information } \\
\text { or materials }\end{array}$ & $\begin{array}{l}\text { Lies that justify the liars' refusal for cooperation because of incomplete } \\
\text { knowledge in the discussed is sue }\end{array}$ & My booklet is not complete \\
\hline Not having, missing, or losing sth & $\begin{array}{l}\text { Lies that show the liars do not have, miss, or lo se something and giving it to } \\
\text { others is impos sible. }\end{array}$ & I have no money. \\
\hline Being busy & $\begin{array}{l}\text { Lies that show liars have no time to work on other issues or pay attention to } \\
\text { other things }\end{array}$ & $\begin{array}{l}\text { I'm really busy in these } \\
\text { days. }\end{array}$ \\
\hline Self-devotion & Lies that justify the actions by pretending the self-devotion & $\begin{array}{l}\text { I took the injured people to } \\
\text { the hospital }\end{array}$ \\
\hline Havingno expertise & Lies that show the liar have no expertise to cooperate with the targets & $\begin{array}{l}\text { Ask others, it's not in the } \\
\text { area of my expertise }\end{array}$ \\
\hline Beingmentally busy & $\begin{array}{l}\text { Lies that justify the actions by pretending to have problems that make the } \\
\text { liar have no focus to do something }\end{array}$ & My mind's busy! \\
\hline Promise & Lies that relate to promises that is told and broken frequently by liars & $\begin{array}{l}\text { I promise to bring it } \\
\text { tomorrow. }\end{array}$ \\
\hline Rejection & Lies that are real lies; the liars completely reject the action & I didn't say it. \\
\hline Being sick & Lies that the liar pretends to be sick and is in bed & I've a bad headache. \\
\hline Exaggeration & Lies that the liar tells to extravagate the fact & You are the best teacher. \\
\hline Being law-obedient & $\begin{array}{l}\text { Lies that liars tell to pretend that they are following the rules while in fact } \\
\text { they always violate them }\end{array}$ & It's against the law. \\
\hline Taking an oath & $\begin{array}{l}\text { Lies that are told by taking an oath to justify the actions and increase the } \\
\text { pos sibility of acceptance of the lie }\end{array}$ & $\begin{array}{l}\text { I swear to my deceased } \\
\text { father, I didn't do that. }\end{array}$ \\
\hline Conceslment & Hiding or concesling the truth & \\
\hline $\begin{array}{l}\text { Complement } \\
\text { Rumoring }\end{array}$ & $\begin{array}{l}\text { Liars say something as a complement while indeed they won't mean to do it } \\
\text { Dispersing a lie among academicians and students }\end{array}$ & $\begin{array}{l}\text { I'm at your service any } \\
\text { time that you like } \\
\text { Math class was cancelled. }\end{array}$ \\
\hline
\end{tabular}




\section{Results}

\subsection{Ranking of lies in academic contexts}

To answer the first research question that was "what are the most frequent lies across The Iranian academic context?" the lies were ranked from the highest to the lowest in terms of frequency of use by both students and professors in Table 2. According to the table, 'projection' lies were the most frequently used lies among students and professors. This type of lie occurred 887 times out of 4115 lies and covered about $21.55 \%$ of all told lies. Other lies are ranked in accordance with their frequency of occurrence as shown in Table 2. Some lies such as 'concealment', 'rumoring' and 'complement' were included in the taxonomy but did not have any frequency on the part of the participants. The reason is that they are among the cases where the questionnaire has not covered.

Table 2. Ranking of professors and students' lies in terms of frequency and percentages

\begin{tabular}{|c|c|c|c|c|c|}
\hline $\begin{array}{c}\text { Ranking of } \\
\text { professors' lies }\end{array}$ & & $\begin{array}{c}\text { Ranking of } \\
\text { students' lies }\end{array}$ & & $\begin{array}{c}\text { Total ranking of } \\
\text { lies }\end{array}$ & \\
\hline Types of lies & RF(\%) & Types of lies & $\mathrm{RF}(\%)$ & Types of lies & RF(\%) \\
\hline Projection & $360(22.48)$ & Projection & $527(20.96)$ & Projection & $887(21.55)$ \\
\hline $\begin{array}{l}\text { Having prionity in } \\
\text { daily works }\end{array}$ & $260(16.23)$ & Forgetting & $343(13.64)$ & Forgetting & $429(10.42)$ \\
\hline Being busy & $153(9.55)$ & Self-devotion & $265(10.54)$ & Self-devotion & $346(8.40)$ \\
\hline Being mentally busy & $135(8.43)$ & $\begin{array}{l}\text { Having incomplete } \\
\text { information or } \\
\text { materials }\end{array}$ & $246(9.78)$ & $\begin{array}{l}\text { Having priority in } \\
\text { daily works }\end{array}$ & $314(7.63)$ \\
\hline Having no expertise & $114(7.12)$ & Exaggeration & $217(8.63)$ & $\begin{array}{l}\text { Having incomplete } \\
\text { information or } \\
\text { materials }\end{array}$ & $293(7.12)$ \\
\hline Forgetting & $86(5.37)$ & Being mentally busy & $136(5.40)$ & Being busy & $275(6.68)$ \\
\hline $\begin{array}{l}\text { Not having, missing, } \\
\text { or losing sth }\end{array}$ & $86(5.37)$ & $\begin{array}{l}\text { Not having, missing, } \\
\text { or losing sth }\end{array}$ & $133(5.29)$ & Being mentally busy & $271(6.58)$ \\
\hline Being law-obedient & $85(5.30)$ & Being sick & $133(5.29)$ & Exaggeration & $230(5.58)$ \\
\hline Being sick & $83(5.18)$ & Being busy & $122(4.85)$ & $\begin{array}{l}\text { Not having, missing, } \\
\text { or losing sth }\end{array}$ & $219(5.32)$ \\
\hline Self-devotion & $81(5.05)$ & Promise & $113(3.42)$ & Being sick & $216(5.24)$ \\
\hline Promise & $74(4.62)$ & Taking an oath & $99(3.93)$ & Promise & $187(4.54)$ \\
\hline $\begin{array}{l}\text { Having incomplete } \\
\text { information or } \\
\text { materials }\end{array}$ & $47(2.93)$ & Rejection & $86(3.42)$ & Having no expertise & $154(3.74)$ \\
\hline Rejection & $24(1.49)$ & $\begin{array}{l}\text { Having priority in } \\
\text { daily works }\end{array}$ & $54(2.14)$ & Rejection & $110(2.67)$ \\
\hline \multirow[t]{4}{*}{ Exaggeration } & $13(.81)$ & Having no expertise & $40(1.59)$ & Being law-obedient & $85(2.06)$ \\
\hline & & & & Concealment & - \\
\hline & & & & Complement & - \\
\hline & & & & Rumoring & - \\
\hline Total & $4115(100 \%)$ & & $1601(100 \%)$ & & $2514(100 \%)$ \\
\hline
\end{tabular}

To see the rank of lies in each specific interaction, the frequency and percentage of each lie were given in the next two tables. Table 3 contains ranking of lies in professors' interactions. According to the table, 'projection' lies ranked first in professor-staff interaction and 'having daily priority in daily works' ranked second. It seems that professors necessitate keeping theirprestige for their colleagues and students by showing that they do their tasks based on the program and obey the priorities. Table 4 indicates that the student-staff interaction includes the least lies. Just 10 out of 18 types of lies occurred in this interaction. 'Projection' lies were the most used lies in student-staff, and student-student interactions while 'exaggeration' was the most frequent lies in student-professor interaction. 
Table 3. Distribution of lies across professors' interactions with staffs, other professors, and students

\begin{tabular}{|c|c|c|c|c|c|}
\hline $\begin{array}{c}\text { Professor-staff } \\
\text { interaction }\end{array}$ & RF $(\%)$ & $\begin{array}{c}\text { Professor-professor } \\
\text { interaction }\end{array}$ & RF $(\%)$ & $\begin{array}{c}\text { Professor-student } \\
\text { interaction }\end{array}$ & RF (\%) \\
\hline Projection & $110(26.25)$ & Projection & $177(21.74)$ & Projection & $73(19.94)$ \\
\hline $\begin{array}{l}\text { Having priority in daily } \\
\text { works }\end{array}$ & $69(16.46)$ & $\begin{array}{l}\text { Having priority in daily } \\
\text { works }\end{array}$ & $134(16.46)$ & $\begin{array}{l}\text { Having priority in daily } \\
\text { works }\end{array}$ & $57(15.57)$ \\
\hline Being busy & $40(9.54)$ & Being busy & $71(8.72)$ & Being mentally busy & $48(13.11)$ \\
\hline Being mentally busy & $40(9.54)$ & Forgetting & $61(7.49)$ & Being busy & $42(11.47)$ \\
\hline Having no expertise & $36(8.59)$ & Having no expertise & $55(6.75)$ & Promise & $18(4.91)$ \\
\hline Being law-obedient & $30(7.15)$ & Being law-obedient & $53(6.51)$ & Self-devotion & $36(9.83)$ \\
\hline Forgetting & $17(4.05)$ & $\begin{array}{l}\text { Not having, missing, or } \\
\text { losing sth }\end{array}$ & $52(6.38)$ & Having no expertise & $23(6.28)$ \\
\hline $\begin{array}{l}\text { Not having, missing, or } \\
\text { losing sth }\end{array}$ & $17(4.05)$ & Promise & $47(5.77)$ & $\begin{array}{l}\text { Having incomplete } \\
\text { information or materials }\end{array}$ & $22(6.01)$ \\
\hline Being sick & $17(4.05)$ & Being mentally busy & $47(5.77)$ & Being sick & $22(6.01)$ \\
\hline $\begin{array}{l}\text { Having incomplete } \\
\text { information or materials }\end{array}$ & $12(2.86)$ & Being sick & $44(5.40)$ & $\begin{array}{l}\text { Not having, missing, or } \\
\text { losing sth }\end{array}$ & $17(4.64)$ \\
\hline Rejection & $9(2.14)$ & Self-devotion & $39(4.79)$ & Forgetting & $6(1.63)$ \\
\hline Promise & $9(2.14)$ & Rejection & $15(1.84)$ & Being law-obedient & $2(0.54)$ \\
\hline Exaggeration & $7(1.67)$ & $\begin{array}{l}\text { Having incomplete } \\
\text { information or materials }\end{array}$ & $13(1.59)$ & & \\
\hline Self-devotion & $6(1.43)$ & Exaggeration & $6(0.73)$ & & \\
\hline Total & $419(100 \%)$ & & $814(100 \%)$ & & $366(100 \%)$ \\
\hline
\end{tabular}

Note: RF: raw frequency, \%: of the overall lies

Table 4. Distribution of lies across students' interactions with staffs, other students, and professors

\begin{tabular}{|c|c|c|c|c|c|}
\hline Student-Staff interaction & RF $(\%)$ & $\begin{array}{c}\text { Student-Student } \\
\text { interaction }\end{array}$ & $\overline{R F(\%)}$ & $\begin{array}{c}\text { Student-Professor } \\
\text { interaction }\end{array}$ & $\overline{R F}(\%)$ \\
\hline Projection & $123(24.74)$ & Projection & $235(23.31)$ & Exaggeration & $217(21.50)$ \\
\hline Self-devotion & $99(19.91)$ & Forgetting & $134(13.29)$ & Forgetting & $141(13.97)$ \\
\hline Forgetting & $68(13.68)$ & $\begin{array}{l}\text { Not having, missing, or } \\
\text { losing sth }\end{array}$ & $112(11.11)$ & Projection & $169(16.74)$ \\
\hline Being busy & $47(9.45)$ & $\begin{array}{l}\text { Having incomplete } \\
\text { information or materials }\end{array}$ & $102(10.11)$ & $\begin{array}{l}\text { Having incomplete } \\
\text { information or materials }\end{array}$ & $111(11)$ \\
\hline Being mentally busy & $35(7.04)$ & Self-devotion & $74(7.34)$ & Self-devotion & $92(9.11)$ \\
\hline $\begin{array}{l}\text { Having incomplete } \\
\text { information or materials }\end{array}$ & $33(6.63)$ & $\begin{array}{l}\text { Having priority in daily } \\
\text { works }\end{array}$ & $54(5.35)$ & Being sick & $61(6.04)$ \\
\hline Being sick & $33(6.63)$ & Taking an oath & $50(4.96)$ & Rejection & $58(5.74)$ \\
\hline Promise & $29(5.83)$ & Being busy & $47(4.66)$ & Being mentally busy & $53(5.25)$ \\
\hline $\begin{array}{l}\text { Not having, missing, or } \\
\text { losing sth }\end{array}$ & $21(4.22)$ & Being mentally busy & $48(4.76)$ & Taking an oath & $40(3.96)$ \\
\hline Taking an oath & $9(1.81)$ & $\begin{array}{l}\text { Promise } \\
\text { Having no expertise } \\
\text { Being sick } \\
\text { Rejection }\end{array}$ & $\begin{array}{l}45(4.46) \\
40(3.96) \\
39(3.86) \\
28(2.77)\end{array}$ & $\begin{array}{l}\text { Promise } \\
\text { Being busy }\end{array}$ & $\begin{array}{l}39(3.86) \\
28(2.77)\end{array}$ \\
\hline Total & $497(100 \%)$ & & $1008(100)$ & & $1009(100)$ \\
\hline
\end{tabular}

\subsection{Distribution of lies across interactions in relation to gender parings}

To answer the second research question that was "Do the frequency and types of lies differ in same-gender parings comparing with different-gender parings?" the frequency and percentage of each lie across gender parings have been computed. Results are given in Tables 5 and 6 . The tables, respectively, indicate the occurrences of lies among professor-staff, professor-professor, professor-student, student-staff, student-student, and student-professor. Each of these interactions consists of four gender parings- M-M, M-F, F-F, and F-M. Distribution of lies across gender parings in each interaction is given below.

\subsubsection{Professor-Staff interaction}

As Table 5 shows, about 419 lies were told in professor-staff interaction, among which most of them told in F-F parings $(\mathrm{N}=130)$, that covered about $31 \%$ of all lies told in this interaction. $\mathrm{M}-\mathrm{F}$ parings covered about $28.63 \%$, M-M told $20.52 \%$ of all lies, and F-M covered the least lies (19.8\%). In M-F interaction, 'projection' lie covered $6.68 \%$ of the lies told between these parings while in F-M it covered $4.77 \%$. This trend also occurred for 'having priority in 
daily works' lie. $4.77 \%$ of the lies in M-F were covered by this lie while the lie covered $2.38 \%$ in F-M interactions. In addition, males pretend that they are busy in interaction with a female staff (it covered $4.05 \%$ ) but females rarely used such strategy $(0.71 \%)$. Regarding being mentally busy, F-F interaction used this lie more than M-M interaction $(1.67 \%$ vs. $3.57 \%)$. 'Having no expertise' lie occurred more in F-F and M-F interactions $(4.05 \%$ and $2.86 \%$, respectively). For 'forgetting' lie, more occurrences were observed in M-F interactions (2.38\%). In F-F interaction, the female professors tended to represent themselves as law-obedient for their same sexes. 'Self-devotion' lie did not occur in the male professor interactions, and rarely was used among female professors.

Table 5. Distribution of lies across professors' interaction regarding gender parings

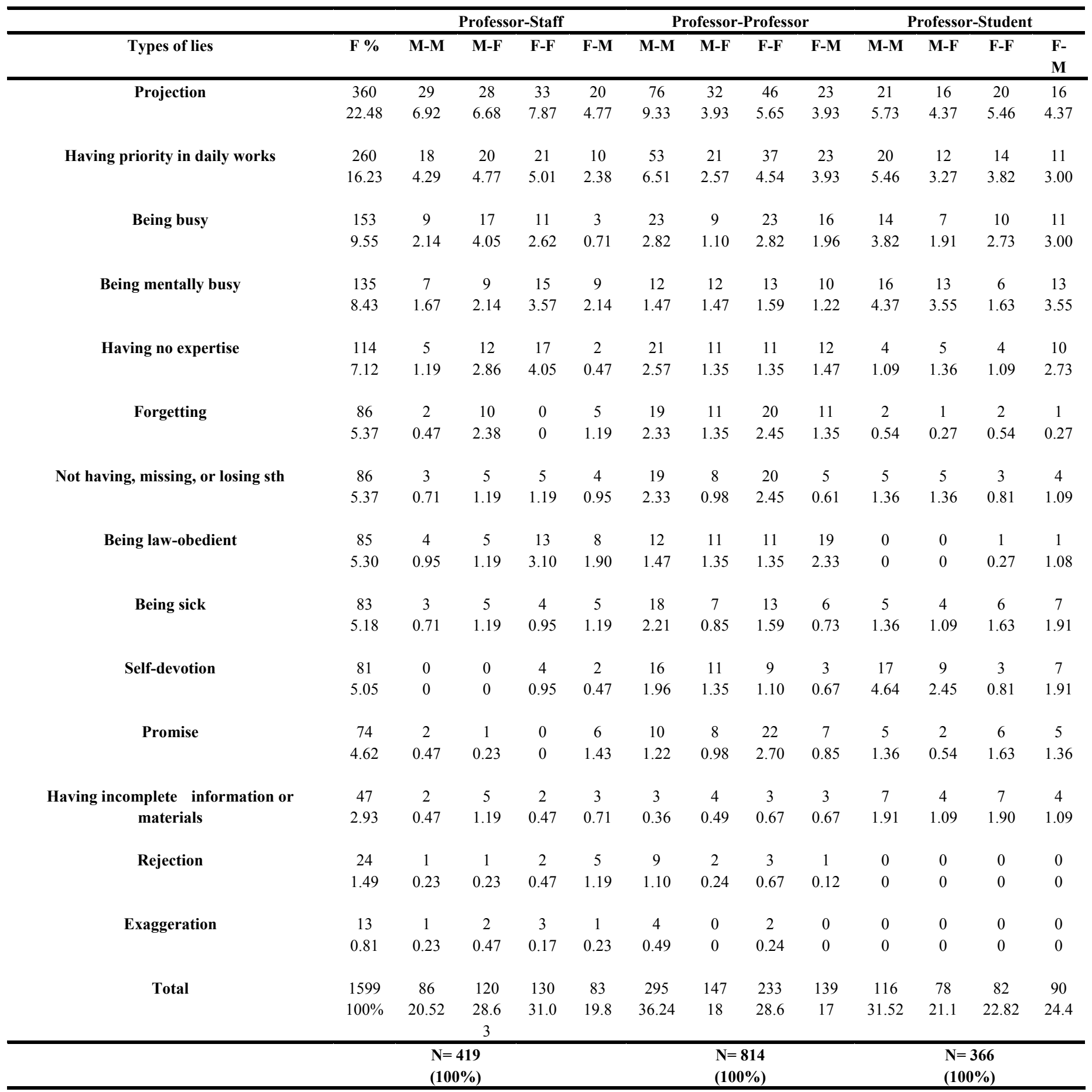

Note: F: frequency, \%: of the overall lies 


\subsubsection{Professor-Professor interaction}

In this interaction, 814 lies were observed that M-M and F-F parings (36.24\% and $28.6 \%)$ showed the higher coverage. In M-M paring, 'projection' lie was the most frequent lie used by male professors in relation with their male colleagues. In this paring, male professors also tried toshow the priority in their daily works and plans in relation with their same-gender colleagueswhile in relation with a female professor this trend is not frequently used. The same difference was also observed in the case of 'having no expertise', 'being busy', 'forgetting', 'not having or losing sth', 'being sick', 'rejection' and 'exaggeration' lies. In F-F paring, similar to M-M paring, the most frequent lie was 'projection'. The female professors told more lies to their same-gender colleagues. In this paring, they pretended to forget something (2.45), promised to cooperate $(2.70 \%)$, and claimed that they had lost or did not have something that their colleagues needed $(2.45 \%)$. Regarding 'law-obedient' lie, female professors used this lie more in relation with their male colleagues $(2.33 \%)$.

Table 6. Distribution of lies across students' interactions

\begin{tabular}{|c|c|c|c|c|c|c|c|c|c|c|c|c|c|}
\hline \multirow[b]{2}{*}{ Types of lies } & \multirow[b]{2}{*}{ F\% } & \multicolumn{4}{|c|}{ Student-Staff } & \multicolumn{4}{|c|}{ Student-Student } & \multicolumn{4}{|c|}{ Student-Professor } \\
\hline & & M-M & M-F & $\mathbf{F}-\mathbf{F}$ & F-M & M-M & M-F & F-F & F-M & M-M & M-F & F-F & F-M \\
\hline \multirow[t]{2}{*}{ Projection } & 527 & 40 & 27 & 24 & 32 & 58 & 47 & 74 & 56 & 45 & 34 & 50 & 40 \\
\hline & 20.96 & 8.04 & 5.43 & 4.82 & 6.43 & 5.75 & 4.66 & 7.34 & 5.55 & 4.45 & 3.36 & 4.95 & 3.96 \\
\hline \multirow[t]{2}{*}{ Forgetting } & 343 & 34 & 0 & 19 & 15 & 44 & 33 & 33 & 24 & 34 & 30 & 39 & 38 \\
\hline & 13.64 & 6.84 & 0 & 3.82 & 3.01 & 4.36 & 3.27 & 3.27 & 2.38 & 3.36 & 2.97 & 3.86 & 3.76 \\
\hline \multirow[t]{2}{*}{ Not having, missing, or losing sth } & 133 & 21 & 0 & 0 & 0 & 31 & 25 & 32 & 24 & 0 & 0 & 0 & 0 \\
\hline & 5.29 & 4.22 & 0 & 0 & 0 & 3.07 & 2.48 & 3.17 & 2.38 & 0 & 0 & 0 & 0 \\
\hline \multirow[t]{2}{*}{ Having incomplete information or materials } & 246 & 0 & 0 & 13 & 20 & 23 & 27 & 27 & 25 & 30 & 20 & 33 & 28 \\
\hline & 9.78 & 0 & 0 & 2,61 & 4.02 & 2.28 & 2.67 & 2.67 & 2.48 & 2.97 & 1.98 & 3.27 & 2.77 \\
\hline \multirow[t]{2}{*}{ Self-devotion } & 265 & 23 & 47 & 18 & 11 & 13 & 23 & 20 & 18 & 18 & 20 & 26 & 28 \\
\hline & 10.54 & 4.62 & 9.45 & 3.62 & 2.21 & 1.28 & 2.28 & 1.98 & 1.78 & 1.78 & 1.98 & 2.57 & 2.77 \\
\hline \multirow[t]{2}{*}{ Having priority in daily works } & 54 & 0 & 0 & 0 & 0 & 14 & 10 & 17 & 13 & 0 & 0 & 0 & 0 \\
\hline & 2.14 & 0 & 0 & 0 & 0 & 1.38 & 0.99 & 1.68 & 1.28 & 0 & 0 & 0 & 0 \\
\hline \multirow[t]{2}{*}{ Rejection } & 86 & 0 & 0 & 0 & 0 & 14 & 0 & 14 & 0 & 16 & 12 & 15 & 15 \\
\hline & 3.42 & 0 & 0 & 0 & 0 & 1.38 & 0 & 1.38 & 0 & 1.58 & 1.18 & 1.48 & 1.48 \\
\hline \multirow[t]{2}{*}{ Being busy } & 122 & 0 & 13 & 0 & 34 & 18 & 13 & 9 & 7 & 6 & 7 & 8 & 7 \\
\hline & 4.85 & 0 & 2.61 & 0 & 6.84 & 1.78 & 1.28 & 0.89 & 0.69 & 0.59 & 0.69 & 0.79 & 0.69 \\
\hline \multirow[t]{2}{*}{ Having no expertise } & 40 & 0 & 0 & 0 & 0 & 9 & 10 & 15 & 6 & 0 & 0 & 0 & 0 \\
\hline & 1.59 & 0 & 0 & 0 & 0 & 0.89 & 0.99 & 1.48 & 0.59 & 0 & 0 & 0 & 0 \\
\hline \multirow[t]{2}{*}{ Being sick } & 133 & 0 & 0 & 16 & 17 & 6 & 9 & 16 & 8 & 15 & 13 & 17 & 16 \\
\hline & 5.29 & 0 & 0 & 3.21 & 3.42 & 0.59 & 0.89 & 1.58 & 0.79 & 1.48 & 1.28 & 1.68 & 1.58 \\
\hline \multirow[t]{2}{*}{ Exaggeration } & 217 & 0 & 0 & 0 & 0 & 0 & 0 & 0 & 0 & 60 & 27 & 70 & 60 \\
\hline & 8.63 & 0 & 0 & 0 & 0 & 0 & 0 & 0 & 0 & 5.94 & 2.67 & 6.93 & 5.94 \\
\hline \multirow[t]{2}{*}{ Being mentally busy } & 136 & 0 & 11 & 12 & 12 & 20 & 14 & 8 & 6 & 16 & 10 & 17 & 10 \\
\hline & 5.40 & 0 & 2.21 & 2.41 & 2.41 & 1.98 & 1.38 & 0.79 & 0.59 & 1.58 & 0.99 & 1.68 & 0.99 \\
\hline \multirow[t]{2}{*}{ Taking an oath } & 99 & 0 & 0 & 9 & 0 & 15 & 6 & 17 & 12 & 12 & 10 & 10 & 8 \\
\hline & 3.93 & 0 & 0 & 1.81 & 0 & 1.48 & 0.59 & 1.68 & 1.19 & 1.18 & 0.99 & 0.99 & 0.79 \\
\hline \multirow[t]{2}{*}{ Promise } & 113 & 17 & 0 & 12 & 0 & 12 & 11 & 13 & 9 & 11 & 6 & 12 & 10 \\
\hline & 4.49 & 3.42 & 0 & 2.41 & 0 & 1.19 & 1.09 & 1.28 & 0.89 & 1.09 & 0.59 & 1.18 & 0.99 \\
\hline \multirow[t]{3}{*}{ Total } & 2514 & 135 & 98 & 123 & 141 & 277 & 228 & 295 & 208 & 263 & 189 & 297 & 260 \\
\hline & $100 \%$ & 27.16 & 19.71 & 24.7 & 28.3 & 27.48 & 22.6 & 29.2 & 20.6 & 26.06 & 18.7 & 29.43 & 25.7 \\
\hline & & \multicolumn{4}{|c|}{ Total $=497(100 \%)$} & \multicolumn{4}{|c|}{ Total $=1008(100 \%)$} & \multicolumn{4}{|c|}{ Total $=1009(100 \%)$} \\
\hline
\end{tabular}

Note: F: frequency, \%: of the overall lies 


\subsubsection{Professor-Student interaction}

This interaction consisted of 366 lies which were lower than the lies told in the other interactions. Male professors tended to use 'having priority in daily works', 'being busy', 'being mentally busy', and 'self-devotion' lies in relation with their male students while in relation with their female students, they used these lies with less frequency. For female professors, 'being mentally busy' $(3.55 \%)$ and 'having no expertise' $(2.73 \%)$ lies were used more in relation with their male students comparing to their female students.

Table 6 indicates the distribution of lies in different gender parings across Student-Staff, Student- Student, and Student-Professor interactions. As Table 6 shows, the students lied more than their professors (2514 vs. 1599). However, like their professors, they tended to use 'projection' lie more frequently than other lies. The results are given in the following sections.

\subsubsection{Student-Staff interaction}

Since the interaction of students with university staffs is limited, some specific lies are used. In M-M paring, students tended to use 'forgetting' lie (6.84\%) while no cases of using such lie were observed in M-F parings. 'Not having or losing sth' lie was just observed in M-M relations (4.22\%). Regarding 'self-devotion' lie, male students used this lie more frequently in relation with female staffs. 'Being busy' lie was only used in relation with opposite genders by both male and female students. 'Being mentally busy' lie was not used in M-M parings and 'promise' lie did not occurred in M-F interaction.

The female students, in contrast to the male students, used 'having incomplete information or materials' and 'being sick' lies in relation to both male and female staffs. They told 'taking an oath' lie to female staffs, a lie that has not been observed in other parings. In F-F interaction, 'promise' lie was used while it has not been used in F-M parings.

\subsubsection{Student-Student interaction}

This interaction consisted of 1008 lies that most of them occurred in F-F (295) and M-M (277) parings. In M-M parings 'rejection' was used while it was absent in M-F relations. Moreover, 'taking an oath' lie was more used in M-M relations than M-F parings. However, in the case of 'self- devotion', male students used this lie more in relation with female students. In F-Fparings, 'rejection' lie was used while it was absent in F-M parings. Other lies such as 'having no expertise', 'bring sick', and 'taking an oath' were more observed in F-F than F-M parings.

\subsubsection{Student-Professor interaction}

This interaction contained 1009 lies included 11 types of lies given in the taxonomy (Table 1). The most frequent lie in this interaction is 'projection' lie (169) and the least frequent was found to be 'being busy' lie (28). Lies told in F-F interaction covered higher coverage among other parings (it covered $29.43 \%$ of lies). M-M interaction produced more lie than M-F interaction (26.06\% vs. $18.7 \%$ ). This difference is highlighted in 'exaggeration' lie. For F-F and F-M parings, slight differences have been observed in the number and percentage of their lies.

All in all, comparing the number and percentage of lies across different parings in different interaction reveals that M-M and F-F parings contained more lies than M-F and F-M. In other words, same genders told more lies to each other than opposite ones. To explore if these differences are significant and to answer the third research question that was "Do same-gender parings tell more lie to each other or different-gender parings?" Chi-square statistical analysis was run (Table 7). As the table shows, these differences regarding M-M and M-F parings across all interactions were significant; however, for F-F and F-M parings, the differences were significant in the cases of the Student-Student, Professor-Staff, and Professor-Professor interactions.

It is also shown that MM-FF differences are only significant for professors' interactions. MM-FM comparisons show that in Student-Student and Professor-Professor interactions the difference is significant. MF-FF differences are significant in Student-Student, Student-Professor, and Professor-Professor interaction. In the case of MF-FM parings, the differences are significant for Student-Staff, Student-Professor, and Professor-Staff interactions. 
Table 7. Chi-Square results for significant differences across different parings

\begin{tabular}{lcccccc}
\hline & \multicolumn{5}{c}{ Types of interactions } \\
\cline { 2 - 7 } Gender parings & Student-Staff & Student-Student & Student-Professor & Professor-Staff & Professor-Professor & Professor-Student \\
\hline MM-MF & $5.87^{*}$ & $4.75^{*}$ & $12.11^{* *}$ & $5.61^{*}$ & $49.55^{* *}$ & $7.44^{* *}$ \\
MM-FF & .55 & .56 & 2.06 & $8.96^{* *}$ & $7.28^{* *}$ & $5.83^{*}$ \\
MM-FM & .13 & $9.81^{* *}$ & .01 & .05 & $62.22^{* *}$ & 3.28 \\
MF-FF & 2.82 & $8.58^{* *}$ & $24.0^{* *}$ & .40 & $19.46^{* *}$ & .40 \\
MF-FM & $7.73^{* *}$ & .91 & $11.22^{* *}$ & $6.74^{* *}$ & .22 & .85 \\
FF-FM & 1.22 & $15.04^{* *}$ & 2.11 & $10.37^{* *}$ & $23.75^{* *}$ & .57 \\
\hline
\end{tabular}

Note: MM: male and male interaction, MF: male and female interaction, FF: female and female interaction, FM:

female and male interaction. ${ }^{*} \mathrm{P}<0.05, * * \mathrm{P}<0.01$

\section{Discussion}

\subsection{Discussing frequency of lies across academic context}

Lying is becoming a commonplace event in social relationships and endangering the honesty and truthfulness in such relations. It is increasingly penetrating to all aspects of life to the point that sometimes people may consider it as the right thing to do. Boone (2011) stated that "unethical behavior can be found in all work environments. Lying ... is so pervasive that those who do it don't think twice about it" (p. 2). To raise individuals' awareness of the permeation of culture of lying, an unrespectable social action, in all aspects of their life, various studies are needed to investigate lying in social communication. Hence, as discussed above, the present study aimed to study lying, among university professors and students, in academic contexts in Iran. Specifically, the study attempted to develop the taxonomy of lies for academic contexts and to determine whether gender plays any role in telling lies. No indications for lying detection are given here. Results showed that 18 types of lies can be detected in academic contexts. The most salient type of lie that received the highest frequency was "projection" (887 times occurred). In this type of lie, liars attribute their inability or undesirability for doing things to the environmental and uncontrollable problems. The projection lies demonstrate that the professors and students dissociate themselves from their words and environment, and some uncontrollable or inaccessible phenomena are called for. In other words, the students and professors deviate their targets' attention to the uncontrollable and out of access issues. Some of these issues can be traffic, Internet problems, accidents, transportation problems etc. High frequency of this lie among The Iranian students and professors is in line with Hancock et al. (2009). They found that some peoplejustify their actions by saying statement such as "my cell phone was on silent mode" or "the net was disconnected".

The second most frequent lie in the taxonomy provided here was "forgetting" (429 times occurred). This lie is not considered as attrition of memory but a common strategy for avoiding telling the truth. Professors and students pretend to forget to do or to bring something while they actually do remember.

The third frequent lie in the taxonomy was self-devotion (it occurred 346 times). For self-devoted lies, liars pretend to protect others and try to arouse the targets' feelings. Gordon and Miller (2000) state that the altruistically-motivated feature of this lie "may allow lie tellers to conclude that their actions were justified or that they had not lied at all. However, those who discover that they have been deceived may not be motivated to consider such flattering interpretations of the deception." (p. 47). Liars of this type try to show off themselves. Self-presentation goals motivate individuals to lie in situations when self-presenters are asked to be appeared as likable and competent (Feldman et al. 2002). Examples of this type of lie can be "my mom's sick. I'm looking after her all the time" or "there was a bad accident on the way home or university. I tried to help. That's why I'm late".

The fourth frequent lie was found to be "having priority in daily works" with 314 occurrences. Similar to Hancock et al. (2009), some professors and students' statements indicate that they are about to do something and have no time for others, though they do not have anything to do. Examples of this type of lie are: I'm preparing an article in these days, I am about to buy new things, I was on a trip! The last example insinuates that the professors prefer that going on a trip is more important than inspecting their students' projects or taking part in the department meetings. Likewise, some professors promise to do something for their colleagues, classmates, or staffs in future but actually they never intend to do so. In the case of "being on a trip" as a strategy for pretending priority in daily works, "abuse of discretion" (using Alpert \& Noble, 2009 words) is implied. They believe that "being on a trip" can be an excusable and justifiable conduct for being absent in a meeting or delay in submitting some documents to the university. However, it is implied that they prefer to "be on a trip" and put off doing the preplanned programs to another time. Nevertheless, it is expected that professors and students exercise judgment and, instead of using deception acts and lying, tell the true reason in every situation. 
Other frequent lies with their frequency of their occurrences are given in Table 2 among which 'being busy' and 'being mentally busy' lies received high coverage. Professors or students, without noting specific reasons, say that they are so (mentally) busy and have no time. This lie was frequently used by students in relation with staffs and male professors in interaction with their male students. 'Making promise' that never abides is another type of lie used in academic context. In this study, it was found that when the intention of making a promise is just a superficial response to the target and the liar never abides his/her words, breaking promise can be regarded as a lie. However, Ekman (1997) disregarded breaking promise as a lie. He highlighted that in circumstances which necessitate changes in policies and tendencies people promise but because of changes in conditions they may break their promises. Respecting Ekman's (1997) view, it seems that he overlooked situations where people advertently promise just to get out of the immediate situation. Within these situations 'making a promise' is regarded as a lie and that is the main reason for the researchers to include "making promise" in the lying taxonomy in this study.

One of the findings of this research is that lies can be context and culture-specific. Some lies such as 'I have no time. My family is waiting for me, I promised to take them out for dinner' and 'I have no time; I have to study lots of books.' during exam season are considered as context-specific lies and lies like 'you are the best professor in this department', 'you are my best friend, that's why I searched into your bag', 'I swear to the soul of my father that I didn't do that', 'the net speed was low, I couldn't check my mail for the last two days' etc. are among the lies which seem to be culture-specific. It is suggested that social environment and culture are two key factors in determining the content of lies. Those lies which are plausible in The Iranian culture may not be acceptable in other cultures.

According to DeMiT, deceptive message planning and production is context-bound and this situated message model helps to understand the deceptive message design. Low-content deceptive acts may be produced in the flow of communication with the addressee and through activation of relevant thoughts and information. The speaker attempted to find the shortest route to bring him/her to a "local best" in particular situations. On the contrary, high-content deceptive acts may require preplanning and preparation. In this case, the deceiver must do his/her best to communicate effectively and pay attention to the consistency and compatibility of the deceptive message with the addressee's knowledge as well as spontaneity in deceptive message execution in order to be believable. From this theoretical framework, therefore, it seems that lies being told in academic contexts are included in low-content deceptive acts though some of them can be viewed as preplanned lies; hence, regarded as high-content deceptive acts. However, what is important here is the issue of "consequence". From DeMiT perspective, deceptive acts have serious and minor consequences. Based on the situation, people may prefer to involve in low- or high-content deceptive acts and through this route they redeem the minor or serious social consequences. While it seems that what has been overlooked here is the time and length of the enactment of the consequences. Both serious and minor consequences can be either immediate or distant. It means that even minor consequences in long terms can have serious consequences. Therefore, what should be taken in serious consideration is the immediate or distant consequences of the deceptive act, not its seriousness or slightness.

\subsection{Gender-parings and lying}

In this study, it was found that same-gender parings in all interactions told more lies. This difference was totally significant for M-M parings comparing to M-F parings. However, insignificant differences were observed between F-M and F-F parings for the Student-Staff, Student-Professor, and Professor-Student interactions (Table 7). It can be implied that the male students and professors tend to disguise truth in interaction with their same genders while this interpretation cannot be true for females in the cases of the Student-Staff, Student-Professor, and Professor-Student interactions. It means that in situations in which context predetermines the content and types of lies gender differences play no role.

High coverage of lies in same-gender parings corroborated DePaulo et al. (1996). They suggested that same-sex paring represents more pronounced differences between men and women than opposite-sex parings. Besides, it is argued that same-sex parings are always interacting with each other, and have more familiarity with each others' characteristics. It can be one of the reasons for higher number of lies in same-sex parings in this study.

As a matter of fact, the findings of the study suggested that gender plays a significant role in lying among professors and students in Iran. The differences in the number and content of lies confirm this conclusion. For instance, in the Student-Student interaction, 'rejection' lie was absent in M-F and F-M parings while in M-M and F-F parings it was frequently used. Likewise, 'being busy' was absent in F-M parings for Professor-Staff interaction. The reason for such differences can be attributed to the basic psychological differences between males and females. In order to be justifiable, liars take these differences into account and choose the most plausible lies during their interaction with same or different genders. 


\subsection{The role of status}

After reviewing the results, one issue that needs to be asked is whether academic status effects on the frequency and types of lies.According to Table 5, professor-student parings contained lowest lies (366) and professor-professor parings revealed the highest frequency of lies (814) in total professors' interactions. One can imply that professors, as one of the higher status people, tend to lie less to lower status people and lie more to the peer-status people. In students' interactions, a high number of lies indicates that in lower status levels people tend to tell lies more than higher status ones. They tell lies to both peer-status and higher status people. It confirms that lies are told to higher status people more than lower ones. On the other words, lower status people use any strategy, even telling lies, to justify their actions for their higher status interlocutors. Therefore, it looks right to claim that status can affect the type and frequency of lies.

\section{Conclusion}

The purpose of the current study was to design a taxonomy for the lies told in the Iranian academic context and evaluate the type and frequency of each lie with regard to gender parings and status. Returning to the questions posed at the beginning of this study, it is now possible to state that 18 types of lies were found to be frequently at use among The Iranian academicians and students alternatively chosen by them on the basis of context, gender, and academic status of the persons. The most obvious finding to emerge from this study is that students and professors tell more lies to those who have high academic status. Whenever students are afraid of their professors and professors feel that their positions are endangered, they try to use untrue statements. This finding can be related to their double-faced behavior. They try to show themselves as responsible people, on the one hand, and tactfully lie to worm out of the responsibility, on the other hand. The findings made it clear that The Iranian academicians and students tell lies about their academic actions to pretend a positive appraisal than a negative one. They try to establish a positive picture of themselves in the mind of their targets and pursue this goal without any disruptions. It seems that if the culture of truthfulness is enacted and maintained among people involved in academic contexts, they do not need to use deception to justify their actions.

Researchers in this study put forwardthat no matter what kind of lie academicians or students tell, frequent use of lies in academic context makes this culture conventionalized which will have destroying effects on the whole society. Professors and students, as two influential agents in establishing culture in each society, should know that dishonesty and lying in their behavior disperse suspiciousness and distrust in society, in general, and in academic contexts, in particular.

The study adds to the body of knowledge that lie classification could help people be aware of the strategies that liars use to justify their actions in academic contexts, also it signifies that developing taxonomy of lies reveals that what lies more frequently are told in what situations and interactions. Findings of such studies can contribute to the language and social studies. From the social psychological perspective, children and adults' language in a society are influenced by the feedback that they receive from their interlocutors. This feedback can be positive or negative. From its positive point of view, if people as social actors know the signs and types of lies, liars cannot mislead them to the wrong directions. The feedback that liars will receive from their interlocutors demands them to think of the consequences of their actions and hopefully change their behavior.

The Iranian students who are studying in culturally-different universities and countries can highly benefit from the findings of this study. They need to care about the intercultural relations and interactions. These students might assume that making excuses for worming out of the responsibility are remedial and will have tinge of consequences. Yet, there are wide cultural differences that may cause mistrust and difficulties.

\subsection{Limitations of the study and suggestions for further research}

This study provided only a snapshot of the presence of lying in professors and students' communication. The results of the study are based on the questionnaire which covered the most frequent and significant interactions in academic contexts. Changing the contexts and reversing the flow of interactions, grouping the interactions instead of paring them, and expanding the questionnaire coverage to all possible interactions may give a broader picture of using lie within and outside of the academic contexts.

Another limitation of the study is that the model presented is limited to the academic contexts in Iran. As discussed earlier, lies are context-specific. Therefore, the model may be incomplete to be used outside of the academic contexts. Additionally, lies are culture-specific. Those lies which are common in Iran may not be told in other cultures. To certify this hypothesis, it is suggested to do further research on this topic cross-culturally. Other limitations are 
related to data collection procedure. Some respondents did not fully answer the questions and refused to have honest cooperation that slowed down the process of doing research.

For further research, exploring the dispersion of lying across the whole society is suggested. One can use case studies for a meticulous and deep evaluation of the lying process, or use conversation analysis for linguistic analysis of lies. A cross-national study can also be another topic. In this way, the role of culture in the diversity of lies and their content can be traced. Direct observation of people while communicating in paring and in the group with or without the presence of opposite gender can be a good topic for investigating lying among people.

\section{References}

Alpert, P. G., \& Noble, J. J. (2009). Lies, true lies, and conscious deception: police officers and the truth. Police Quarterly, 12(2), 237-254. http://dx.doi.org/10.1177/1098611108327315

Anolli, L., Balconi, M., \&Ciceri, R. (2001). Deceptive miscommunication theory (DeMiT): A new model for the analysis of deceptive communication. In L. Anolli, R. Ciceri and G. Riva (Eds.), Say not to Say: New Perspectives on Miscommunication (pp. 76-105). IOS Press.

Bond, F. C., \& Atoum, O. A. (2000). International deception. Personality and Social Psychology Bulletin, 26(3), 385-395. http://dx.doi.org/10.1177/0146167200265010

Boone, M. (2011). Lying destroys integrity. Professionalization of Exercise Physiology, 14(11), 1-10.

DePaulo, B. M., Kashy, D. A., Kirkendol, S. E., Wyer, M. M., \& Epstein, J. A. (1996). Lying in everyday life. Journal of Personality and Social Psychology, 70(5), 979-995. http://dx.doi.org/10.1037/0022-3514.70.5.979

Ekman, P. (1997). Deception, Lying And Demeanor. In States of Mind: American and Post-Soviet Perspectives on Contemporary Issues in Psychology . D.F. Halpern and A.E.Voiskounsky (Eds.) pp. 93-105. New York: Oxford University Press.

Escalera, E. A. (2009). Gender differences in children's use of discourse markers: separate worlds or different contexts? Journal of Pragmatics, 41(12), 2479-2495. http://dx.doi.org/10.1016/j.pragma.2006.08.013

Feldman, S. R., Forrest, A. J., \& Happ, R. B. (2002). Self-presentation and verbal deception: do self-presenters lie more?.Basic and Applied Social Psychology, 42(2), 163-170. http://dx.doi.org/10.1207/S15324834BASP2402_8

Forrest, A. J., \& Feldman, S. R. (2000). Detecting deception and judge's involvement: lower task involvement leads to better lie detection. Personality and Social Psychology Bulletin, 26(1), 118-125. http://dx.doi.org/10.1177/0146167200261011

Gordon, K. A., \& Miller, G. A. (2000). Perspective differences in the construal of lies: is deception in the eye of the beholder. Personality and Social Psychology Bulletin, 26(1), 46-55. http://dx.doi.org/10.1177/0146167200261005

Hancock, T. J., Curry, E. L., Goorha, S., \& Woodworth, M. (2008). On lying and being lied to: A linguistic analysis of deception in computer-mediation communication. Discourse Processes, 45(1), 1-23. http://dx.doi.org/10.1080/01638530701739181

Hancock, T. J., Birnholtz, J., Bazarova, N., Guillory, J., Perlin, J., \& Amos, B. (2009). Butler lies: awareness, deception, and design. Proceedings of ACM CHI, pp. 517-526. NY: ACM Press. http://dx.doi.org/10.1145/1518701.1518782

Hart, L. C., Fillmore, G. D., \& Griffith, D. J. (2009). Indirect detection of deception: looking for change. Current Research in Social Psychology, 14(9), 134-142.

Johannesson, M., \&Dreber, G. (2008). Gender differences in deception. Economic Letters, 99, 197-199. http://dx.doi.org/10.1016/j.econlet.2007.06.027

Kupfer, J. (1982). The Moral Presumption Against Lying. Review of Metaphysics, 36, 103-26.

Mahon, E. J. (2007). A definition of deceiving. International Journal of Applied Philosophy, 21(2), 181-194. http://dx.doi.org/10.5840/ijap20072124

Mahon, E. J. (2008). Two definitions of lying.International Journal of Applied Philosophy, 22(2), 211-230. http://dx.doi.org/10.5840/ijap200822216

Mealy, M., Stephan, W., \& Urrutia, I. C. (2007). The acceptability of lies: a comparison of Ecuadorians and Euro-Americans. International Journal of Intercultural Relations, 31, 689-702. 
http://dx.doi.org/10.1016/j.ijintrel.2007.06.002

Meibauer, J. (2005). Lying and falsely implicating. Journal of Pragmatics, 37, 1373-1399. http://dx.doi.org/10.1016/j.pragma.2004.12.007

Newman, L. M., Pennebaker, W. J., Berry, S. D., \& Richards, M. J. (2003). Lying words: predicting deception from linguistics styles. Personality and Social Psychology, 29(5), 665-675. http://dx.doi.org/10.1177/0146167203251529

Proceedings of the Workshop on Computational Approaches to Deception Detection. (2012). April 23, 2012, Avignon - France.

Sharon, I., \& Amir, Y. (1988). Cross-cultural replications: a prerequisite for the validation of social psychological laws. In M. H. Bond (Ed.), The cross-cultural challenge to social psychology (96-108). Beverly Hills, CA: Sage.

Vrij, A., Edward, K., Roberts, P. K., \& Bull, R. (2000). Detecting deceit via analysis of verbal and nonverbal behavior. Journal of Nonverbal Behavior, 24(4), 239-263. http://dx.doi.org/10.1023/A:1006610329284 